\title{
Changes in central corneal thickness and refractive error after thin-flap laser in situ keratomileusis in Chinese eyes
}

\author{
Ming-Hui Zhao*, Qiang Wu, Li-li Jia and Ping Hu
}

\begin{abstract}
Background: Refractive stability is influenced by alterations in corneal curvature and corneal thickness after laser in situ keratomileusis (LASIK). The aim of this study was to analyze the changes of central corneal thickness (CCT) and refractive error following thin-flap LASIK surgery in Chinese eyes.

Methods: One hundred and fifty-eight myopic patients (302 eyes) who underwent thin-flap LASIK surgery were prospectively evaluated. CCT was measured by non-contact specular microscopy before, and 1 day, 1 week, and 1 , 3 , and 6 months following surgery. Age, refractive error, and optic zone diameter were also recorded.

Results: Preoperatively, the mean CCT was $531.6 \pm 24.3 \mu \mathrm{m}$. At 1 day, 1 week, and 1, 3, and 6 months after surgery, mean CCTs were $431.4 \pm 38.4 \mu \mathrm{m}, 422.6 \pm 37.8 \mu \mathrm{m}, 427.2 \pm 38.0 \mu \mathrm{m}, 434.4 \pm 38.2 \mu \mathrm{m}$, and $435.6 \pm 38.0 \mu \mathrm{m}$, respectively. Significant changes were detected in CCT values at each time point after thin-flap LASIK treatment $(P<0.05)$. The mean preoperative spherical equivalent (SE) was $-5.73 \pm 2.30$ diopters (D). At 1 day, 1 week, and 1, 3, and 6 months after surgery, it was $0.26 \pm 0.58 \mathrm{D}, 0.54 \pm 0.52 \mathrm{D}, 0.49 \pm 0.53 \mathrm{D}, 0.45 \pm 0.49 \mathrm{D}$, and $0.37 \pm 0.42 \mathrm{D}$, respectively. The spherical equivalent refraction at 6 months postsurgery was close to the predicted value $(0.34 \pm 0.30 \mathrm{D})$. The changes in CCT within 6 months $(4.06 \pm 9.99 \mu \mathrm{m})$ were negatively correlated with age, preoperative refractive error, and optical zone diameter, respectively $(r=-0.180, P<0.05 ; r=-0.187, P<0.001 ; r=-0.171, P<0.05$, respectively). No significant correlation was found between CCT changes and SE changes at different time points, postoperatively.
\end{abstract}

Conclusions: CCTs decreased significantly at 1 day after surgery, and continued to decline at 1 week after surgery, then increased over time. From postoperative 1 week, SE over time continually shifted to the myopic side.

Keywords: Central corneal thickness, Myopia, Non-contact specular microscope, Thin-flap laser in situ keratomileusis, Refractive error

\section{Background}

Laser in situ keratomileusis (LASIK) is a common procedure in refractive surgery [1]. It is known that LASIK can be associated with a rare but visually debilitating refractive instability called ectasia. To prevent corneal ectasia after LASIK, it is recommended that at least $250 \mu \mathrm{m}$ of residual corneal stromal tissues should be left after ablation. Therefore, the thinner the corneal flap, the thicker the residual corneal stromal bed can be ablated. This is especially important for treating a high degree of myopia. Thin-flap LASIK can create thinner

\footnotetext{
* Correspondence: zhao_m_h@aliyun.com

Department of Ophthalmology, Shanghai Jiaotong University Affiliated Sixth People's Hospital, Shanghai, 200233, China
}

corneal flaps, thicker residual stroma beds, and its safety and efficacy are similar to those of normal LASIK [2].

Refractive stability is influenced by alterations in corneal curvature and corneal thickness, and refractive error usually takes up to 6 months to stabilize after LASIK. The present study aimed to determine the changes in central corneal thickness (CCT) and spherical equivalent (SE) values in Chinese patients following thin-flap LASIK surgery, to evaluate the associations between postoperative CCT changes with age, preoperative SE, and optical zone diameter, and to evaluate the associations between postoperative CCT changes with postoperative refractive error changes. 


\section{Methods \\ Subjects}

Between May and November 2013, a total of 158 myopic patients (302 eyes) were enrolled in this study. Inclusion criteria were as follows: age $\geq 18$ years; stable refraction for at least 2 years; myopia spherical power between -1.50 and $-12.00 \mathrm{D}$; corneal astigmatism less than -4.00 diopters (D); and best-corrected visual acuity (BCVA) $\geq 0.6$. Exclusion criteria were as follows: ocular examination suggesting any abnormality in at least one eye (e.g., keratoconus or glaucoma); contact lenses worn within the previous 2 weeks; prior ocular and/or corneal surgery; $\mathrm{CCT}<450 \mu \mathrm{m}$ (measured by ultrasound pachymetry); any active systemic disease that may affect corneal wound healing; or severe dry eye syndrome. Ethical approval for the study was obtained from the Shanghai Clinical Research Center. All subjects were volunteers and informed consents were obtained. The study adhered to the tenets of the Declaration of Helsinki.

\section{Procedures}

Preoperatively, all patients had an ophthalmological examination, including uncorrected visual acuity (UCVA) and BCVA, slit-lamp examination, manifest and cycloplegic refraction measurements (Autorefractor Keratometer Topcon KR-8800; Topcon Ltd., Tokyo, Japan), corneal topography (Allegro Topolyzer ${ }^{\mathrm{Tm}}$; WaveLight ${ }^{\oplus}$ Inc., Erlangen, Germany), non-contact intraocular pressure (IOP) measurements (Canon TX-F Full Auto Tonometer; Canon Ltd., Tochigiken, Japan), corneal diameter measurements (Allegro Topolyzer ${ }^{\mathrm{Tm}}$ ), and wavefront analyses (Allegro Analyzer). CCT in both eyes was measured with a non-contact specular microscope (Topcon SP-2000P; Topcon). In the non-contact specular microscopy study, the subject was positioned with his or her chin in a cup, and the forehead was placed against a headband. CCT and endothelial cell density were measured simultaneously. Only CCT readings were used. Each eye was measured three times. The mean of three readings was obtained for further analyses. All measurements were made by the same ophthalmologist.

LASIK was performed by a single surgeon at a single center using the Moria M2 single-use head $90 \mu \mathrm{m}$ microkeratome, and subsequent photoablation was conducted with the Allegretto Wave ${ }^{\bullet}$ Eye-Q excimer laser (Wavelight Laser Technologie AG, Erlangen, Germany). All eyes were treated in a routine manner, optical zone diameters ranged from $6.0 \mathrm{~mm}$ to $7.0 \mathrm{~mm}$, and the transition zone was $1.5 \mathrm{~mm}$ and centered on the patient's pupil. Postoperatively, patients received prednisolone acetate $(1 \%)$ and moxifloxacin $(0.5 \%)$ four times daily for 1 week, along with artificial tears as needed.
CCT and refractive errors were measured at 1 day, 1 week, and at 1,3 , and 6 months after surgery. CCT was measured by the non-contact specular microscope. The optical zone diameter was also measured. All measurements were made by the same ophthalmologist (Huijun Liu).

\section{Data analysis}

Statistical analyses were performed using Statistical Package for Social Sciences version 11.0 software (SPSS Inc., Chicago, IL, USA). The one-sample Kolmogorov-Smirnov test was used to test normal distribution. Data were expressed as the mean \pm standard deviation (SD). A paired $t$-test was used to compare the preoperative CCT values with 1 day postoperative values, and SE values at 6 months after surgery with the predicted SE values. CCT and SE values at different postoperative time points were compared with each other by using analysis of variance (ANOVA) with Bonferroni post hoc tests. The changes in $\mathrm{CCT}$ and SE within 6 months $(\triangle \mathrm{CCT}$ and $\triangle \mathrm{SE}$, respectively) were defined as the differences between postoperative 1 day to 6 months for CCT and SE values, respectively (6 months postoperative value minus 1 day postoperative value). Pearson's partial analyses were used to evaluate the associations between $\triangle \mathrm{CCT}$ and the following parameters: age, preoperative SE, and optical zone diameter. Pearson's correlation analyses were performed to examine the relationships between CCT changes and SE changes (different time point postoperative value minus 1 day postoperative value). A $P<0.05$ was defined as statistically significant.

\section{Results}

All data were distributed normally. The average age of the 158 patients in this study was $29.9 \pm 7.5$ years (range, 18 to 52 years). 52 patients (102 eyes) were males and 106 (200 eyes) were females. The mean preoperative spherical power was $-5.41 \pm 0.88 \mathrm{D}$ (range, -1.50 to $-12.00 \mathrm{D}$ ). The mean cylinder power was $-0.76 \pm 0.29 \mathrm{D}$ (range, 0.00 to $-3.50 \mathrm{D}$ ). The mean SE (spherical power + half cylinder power) was $-5.73 \pm 2.30 \mathrm{D}$ (range, -1.55 to $-12.38 \mathrm{D}$ ). Baseline preoperative characteristics of patients are shown in Table 1.

No free or incomplete flaps, or flaps with buttonholes occurred in this study. The CCT was found to

Table 1 Baseline preoperative characteristics of patients

\begin{tabular}{llll}
\hline Parameters & Female & Male & Total \\
\cline { 2 - 4 } & $(n=106)$ & $(n=52)$ & $(n=158)$ \\
\hline Age (years) & $31.2 \pm 7.6$ & $26.2 \pm 5.8$ & $29.9 \pm 7.5$ \\
Spherical power & $-5.68 \pm 2.21$ & $-4.66 \pm 2.06$ & $-5.41 \pm 0.88$ \\
Cylinder power & $-0.73 \pm 0.82$ & $-0.73 \pm 0.43$ & $-0.76 \pm 0.29$ \\
SE & $-5.77 \pm 2.60$ & $-5.06 \pm 2.02$ & $-5.73 \pm 2.30$ \\
\hline
\end{tabular}

Mean value \pm standard deviation; $\mathrm{SE}$, spherical equivalent 
be $531.6 \pm 24.3 \mu \mathrm{m}$ during the preoperative period. The CCT decreased significantly at 1 day after surgery $(431.4 \pm 38.4 \mu \mathrm{m}, P<0.05)$, and continued to decline at 1 week after surgery $(422.6 \pm 37.8 \mu \mathrm{m})$. At 1 month after surgery, CCT values significantly increased $(427.2 \pm 38.0 \mu \mathrm{m}, P<0.05)$, and continually increased at 3 and 6 months after surgery $(434.4 \pm 38.2 \mu \mathrm{m}$, $P<0.05$, and $435.6 \pm 38.0 \mu \mathrm{m}, \quad P<0.05$, respectively) (Fig. 1). Significant changes were detected in CCT values at each time point after thin-flap LASIK treatment $(P<0.05)$. The mean $\triangle \mathrm{CCT}$ was $4.06 \pm 9.99 \mu \mathrm{m}$.

The mean preoperative SE was $-5.83 \pm 2.30 \mathrm{D}$. At 1 day and 1 week postsurgery, it was $0.26 \pm 0.58 \mathrm{D}$ and $0.54 \pm 0.52 \mathrm{D}$, respectively. There was a myopic shift over time. At 1,3 , and 6 months after treatment, the mean SE was $0.49 \pm 0.53 \mathrm{D}, 0.45 \pm 0.49 \mathrm{D}$, and $0.37 \pm 0.42$ D, respectively (Fig. 2). We did not detect any significant change in SE at any time point after LASIK treatment $(P>0.05)$. SE values at 6 months after surgery were similar to the predicted SE values (predicted SE: $0.34 \pm 0.30 \mathrm{D}$, $P>0.05)$. The mean $\triangle \mathrm{SE}$ was $0.14 \pm 0.57 \mathrm{D}$.

$\triangle \mathrm{CCT}$ negatively correlated with age, preoperative SE, and optical zone diameter $(\mathrm{r}=-0.180, P<0.05 ; \mathrm{r}=-0.187$, $P<0.001$; and, $\mathrm{r}=-0.171, P<0.05$, respectively). Table 2 lists increased CCT values of different preoperative SEs. Table 3 lists increased CCT values of different optical diameter zones.

We did not detect any significant correlations between CCT changes and SE changes (different time point postoperative value minus 1 day postoperative value), when measured at different examination points $(\mathrm{r}=-0.087, P$ $=0.054$ ). No regression occurred within 6 months. All patient UCVAs after surgery were better than 16/20.

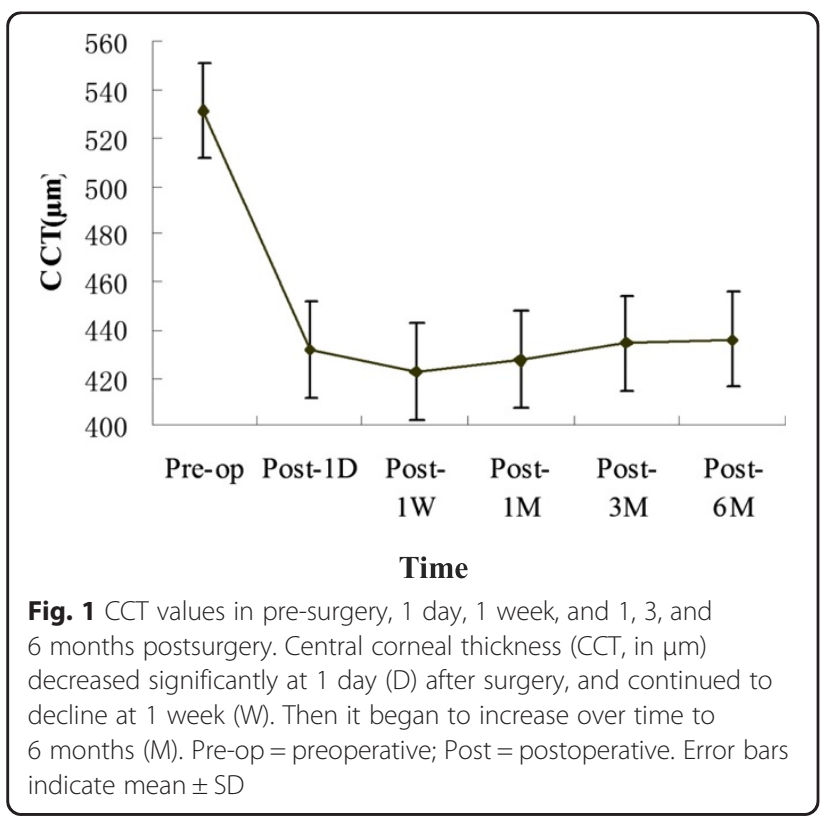

\section{Discussion}

Many types of methods can be used to measure corneal thicknesses, such as ultrasound pachymetry, anteriorsegment optical coherence tomography (AS-OCT), Pentacam measurements, Orbscan measurements, and noncontact specular microscopy techniques. However, the values are not always consistent between the different instruments. In a long-term follow-up study, it was recommended to uniformly use the same kind of measuring instrument [3-5]. Non-contact specular microscopy is a commonly used method for corneal thickness measurement, with advantages including noninvasiveness, ease of operator use, and good examiner-independent reproducibility [6]. Non-contact specular microscopy can be an ideal technique for studying the corneal thickness changes after photorefractive keratectomy, because it is noninvasive, which is especially important during the early postsurgery stage. Changes of CCT values are very important for observation of corneal tissue healing responses after surgery.

In this study, we used non-contact specular microscopy to follow-up the CCT changes within 6 months post thin-flap LASIK treatment. We found that CCT values declined significantly at 1 day postsurgery, and continued to decline at 1 week. CCT values began to increase over time. Several processes occurred during the early postoperative period, including resorption of fluid introduced by intraoperative irrigation, biomechanical hydration shift, epithelial thickness modulation in response to laser ablation, and interface reflectivity changes. However, in many reported cases, the systematic changes are small after 1 week [7], and the posterior stroma is significantly thickened after 1 week postsurgery $[8,9]$. Peng et al. [10] reported that just after LASIK surgery, keratocytes were activated by cytokines that induced collagen fiber synthesis. Keratocyte activation was strongest at 1 to 2 weeks, and persisted until 3 months after LASIK surgery $[8,9]$. This could cause the increase in posterior stromal thickness, and may be why the CCT values continued to increase after 1 week postsurgery.

In this study, we show that from 1 week postoperatively, SE continually shifted to the myopic side over time. Corneal wound repair is believed to be a contributing factor in the gradual increase of corneal thickness and postoperatively in the development of refractive regression [11, 12]. Epithelial hyperplasia after photorefractive keratectomy (PRK) has been suggested to contribute to the loss of the postoperative refractive effect [13-16]. However, after LASIK surgery, epithelial changes were significantly reduced, and were not the main cause for refractive instability [17]. Avunduk et al. reported no significant changes in epithelial thicknesses at any time point after LASIK 


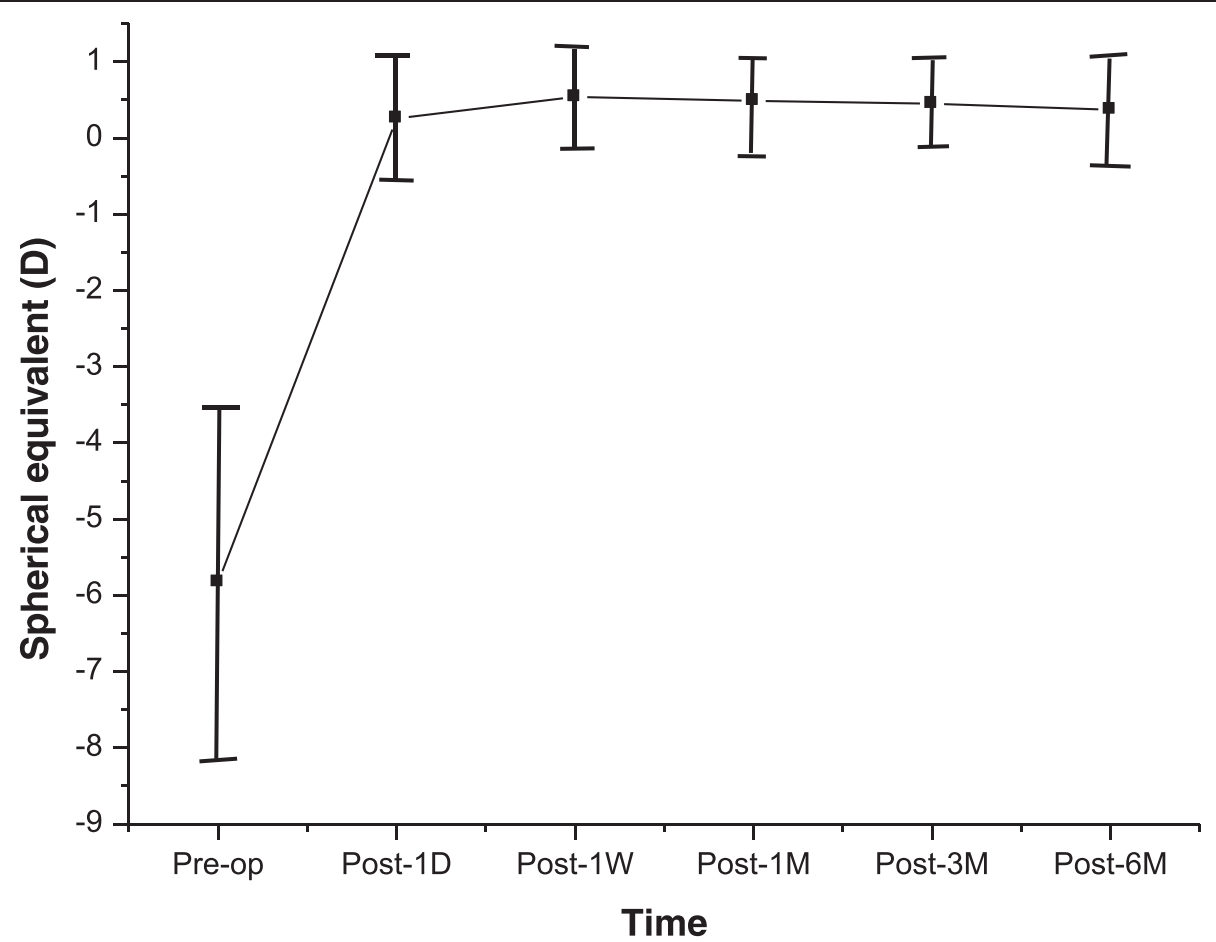

Fig. 2 Changes of spherical equivalents (in diopters, D) for up to 6 months after surgery. From 1 week (W) postsurgery, there was a myopic shift over time to 6 months $(M)$. Pre-op = preoperative; Post = postoperative. Error bars indicate mean \pm SD

treatment [18]. MØller-Pedersen et al. demonstrated activated keratocyte-mediated rethickening of the photoablated stroma of myopic individuals [11]. They further demonstrated that corneal rethickening caused myopic regression mediated almost solely by stromal rethickening; only a minor contribution appeared to originate from restoration of the postoperative epithelial thickness [11]. In the present study, we found a significant increase in the CCT between 1 week and 6 months after surgery $(422.6 \mu \mathrm{m}$ versus $435.6 \mu \mathrm{m})$. The spheroequivalent refraction changed to the myopic side between these time points $(0.54 \mathrm{D}$ versus $0.37 \mathrm{D})$, but the difference did not reach statistical significance, and no significant correlation was detected between the $\mathrm{SE}$ value changes and the $\mathrm{CCT}$ value changes at different examination time points. Normally, it would be expected that a $10 \mu \mathrm{m}$ to $15 \mu \mathrm{m}$ rethickening of the posterior stroma would

Table $\mathbf{2}$ CCT increased values of different preoperative SE

\begin{tabular}{lllll}
\hline & 1 week & 1 month & 3 months & 6 months \\
\hline$>-3.00 \mathrm{D}$ & $-11.28 \pm 4.23$ & $-7.70 \pm 5.07$ & $0.22 \pm 5.64$ & $3.75 \pm 7.19$ \\
$-3.00 \mathrm{D}$ to $-6.00 \mathrm{D}$ & $-8.41 \pm 6.21$ & $-3.86 \pm 6.25$ & $1.59 \pm 6.13$ & $4.75 \pm 7.27$ \\
$<-6.00 \mathrm{D}$ & $-6.94 \pm 9.69$ & $-2.11 \pm 6.15$ & $4.44 \pm 7.43$ & $6.51 \pm 9.61$ \\
\hline
\end{tabular}

Mean value \pm standard deviation $(\mu \mathrm{m}) ; \mathrm{D}=$ diopters; $\mathrm{CCT}=$ central corneal thickness; $\mathrm{SE}=$ spherical equivalent. Values are different postoperative time point CCT values minus CCT values at 1 day postsurgery produce a $1 \mathrm{D}$ myopic shift. However, in the present study, the much greater rethickening created only a small amount of refractive change. It is difficult to explain this refractive change with activated keratocytemediated rethickening of the photoablated posterior stroma. Avunduk et al. suggested that the most probable explanation is that the refractive change is induced by different refractive characteristics of activated keratocytes during LASIK surgery. Therefore, the anterior and posterior curvature and the refractive index may be shifting postsurgery, and these factors may also play a role [18]. However, we do not have any corneal curvature measurements to support this hypothesis.

$\mathrm{Li}$ et al. found that CCT increased within 12 months after LASIK surgery, and was correlated with age, preoperative SE, and corneal bed thickness $(\mathrm{r}=-0.554$, $r=0.382, r=-0.352$, respectively) [19]. Our present observations were similar, however, in our study the correlations were all weak $(r<0.2)$. The reason for this difference is unclear, and further study is needed to confirm this finding. In elderly patients, tissue regeneration ability is reduced therefore the possibility of refractive regression is lower. It is not recommended to overcorrect on LASIK in patients over 40 years old [14]. To prevent the occurrence of refractive regression after surgery in patients with high myopia, it is recommended to expand the optical zone diameter as large as possible, 
Table 3 CCT increased values at different optical diameter zones $(\mu \mathrm{m})$

\begin{tabular}{lllll}
\hline zone & 1 week & 1 month & 3 months & 6 months \\
\hline $6.0 \mathrm{~mm}$ & $-6.76 \pm 6.03$ & $-2.83 \pm 6.14$ & $5.16 \pm 7.46$ & $4.84 \pm 7.51$ \\
$6.5 \mathrm{~mm}$ & $-7.04 \pm 6.34$ & $-3.61 \pm 6.37$ & $4.57 \pm 8.10$ & $5.28 \pm 11.58$ \\
$7.0 \mathrm{~mm}$ & $-8.77 \pm 6.68$ & $-5.64 \pm 6.68$ & $1.28 \pm 6.40$ & $1.38 \pm 7.81$
\end{tabular}

Values are different postoperative time point CCT values minus CCT values at 1 day postsurgery at the three indicated zones. $\mathrm{CCT}=$ central corneal thickness

leaving sufficient corneal stromal tissues. We also retained a certain degree diopter that was corrected after surgery with eye glasses [15].

\section{Conclusion}

In conclusion, CCT decreased significantly at 1 day after surgery, and continued to decline at 1 week after surgery, then it increased over time. From 1 week postoperative, SE continually shifted to the myopic side, with increased time postsurgery.

\section{Abbreviations}

LASIK: Laser in situ keratomileusis; CCT: Central corneal thickness; SE: Spherical equivalent; UCVA: Uncorrected visual acuity; BCVA: Best-corrected visual acuity; SD: Standard deviation; ANOVA: Analysis of variance; AS-OCT: Anterior-segment optical coherence tomography.

\section{Competing interests}

The authors declare that they have no competing interests.

\section{Authors' contributions}

MH Z conceived of the study, and participated in its design. QW participated in the design of the study. LL J participated in the study design and coordination. PH performed the statistical analyses. All authors read and approved the final manuscript.

\section{Acknowledgements}

The authors thank Ying Huang (Shanghai Jiaotong University Affiliated Sixth People's Hospital, Shanghai, China) for her valuable suggestions and Liang Wang (Austin Diagnostic Clinic, Austin, Texas, USA) for suggesting editing changes to this manuscript.

Received: 27 January 2015 Accepted: 20 July 2015

Published online: 29 July 2015

\section{References}

1. Duffey RJ, Leaming D. US trends in refractive surgery: 2003 ISRS /AAO survey. J Refract Surg. 2005;21:87-91.

2. Azar DT, Ghanem RC, de la Cruz J, Hallak JA, Kojima T, Al-Tobaigy FM, et al. Thin-flap (sub-Bowman keratomileusis) versus thick-flap laser in situ keratomilusis for moderate to high myopia: case-control analysis. J Cataract Refract Surg. 2008;34:2073-78.

3. Modis Jr L, Langenbucher A, Seitz B. Scanning-slit and specular microscopic pachymetry in comparison with ultrasonic determination of corneal thickness. Cornea. 2001;20:711-14.

4. Zhao MH, Zou J, Wang WQ, Li J. Comparison of central corneal thickness as measured by non-contact specular microscopy and ultrasound pachymetry before and post-LASIK. Clin Experiment. 2007;35(9):818-23.

5. Thomas J, Wang J, Rollins AM, Sturm J. Comparison of corneal thickness measured with optical coherence tomography, ultrasonic pachymetry, and scanning slit method. J Refract Surg. 2006:22:671-78.

6. Tam ES, Rootman DS. Comparison of central corneal thickness measurements by specular microscopy, ultrasound pachymetry, and ultrasound biomicroscopy. J Cataract Refract Surg. 2003;29:1179-84.
7. Li Y, Netto MV, Shekhar R, Krueger RR, Huang D. A longitudinal study of LASIK flap and stromal thickness with high-speed optical coherence tomography. Ophthalmology. 2007;114:1124-32.

8. Vesaluoma MH, Perez-Santonja JJ, Petroll WM, Linna T, Alio JL, Tervo TMT. Corneal stromal changes induced by myopic LASIK. Invest Ophthalmol Vis Sci. 2000;41:369-76.

9. Vesaluoma MH, Petroll WM, Perez-Santonja JJ, Valle TU, Alio JL, Tervo TMT LASIK flap margin: wound healing and complications imaged by in vivo confocal microscopy. Am J Ophthalmol. 2000;130:564-73.

10. Kent DG, Solomon KD, Peng Q, Whiteside SB, Brown SJ, Apple DJ. Effect of surface photorefractive keratectomy and laser in situ keratomileusis on the corneal endothelium. J Cataract Refract Surg. 1997;23:386-97.

11. Møller-Pedersen T, Cavanagh HD, Petroll WM, Jester JV. Stromal wound healing explains refractive instability and haze development after photorefractive keratectomy: a 1-year confocal microscopic study. Ophthalmology. 2000;107:1235-45.

12. Netto MV, Mohan RR, Ambrosio Jr R, Hutcheon AE, Zieske JD, Wilson SE. Wound healing in the cornea: a review of refractive surgery complications and new prospects for therapy. Cornea. 2005;24:509-22.

13. Lohmann CP, Reischl U, Marshall J. Regression and epithelial hyperplasia after myopic photorefractive keratectomy in a human cornea. J Cataract Refract Surg. 1999;25:712-15.

14. Gauthier CA, Holden BA, Epstein D, Tengroth B, Fagerholm P, Hamberg-Nystrom $\mathrm{H}$. Role of epithelial hyperplasia in egression following photorefractive keratectomy. Br J Ophthalmol. 1996;80:545-48.

15. Dierick HG, Van Mellaert CE, Missotten L. Histology of rabbit corneas after 10-diopter photorefractive keratectomy for hyperopia. J Refract Surg. 1999;15:459-68.

16. Dierick HG, Missotten L. Is the corneal contour influenced by a tension in the superficial epithelial cells? A new hypothesis. Refract Corneal Surg. 1992;8:54-9.

17. Ivarsen A, Fledelius W, Hjortdal JØ. Three-year changes in epithelial and stromal thickness after PRK or LASIK for high myopia. Invest Ophthalmol Vis Sci. 2009:50:2061-66

18. Avunduk AM, Senft CJ, Emerah S, Varnell ED, Kaufman HE. Corneal healing after uncomplicated LASIK and its relationship to refractive changes: a six-month prospective confocal study. Invest Ophthalmol Vis Sci. 2004:45:1334-39.

19. Li L, Xie LM, Yang B, Deng Y. Change of corneal thickness after laser in situ keratomileusis. Chin J Ophthalmol. 2004;40:17-9.

\section{Submit your next manuscript to BioMed Central and take full advantage of:}

- Convenient online submission

- Thorough peer review

- No space constraints or color figure charges

- Immediate publication on acceptance

- Inclusion in PubMed, CAS, Scopus and Google Scholar

- Research which is freely available for redistribution 